\title{
Maternal cadmium, iron and zinc levels, DNA methylation and birth weight
}

\author{
Adriana C. Vidal ${ }^{1}$, Viktoriya Semenova ${ }^{2,3}$, Thomas Darrah ${ }^{4}$, Avner Vengosh ${ }^{5}$, Zhiqing Huang ${ }^{6}$, Katherine King ${ }^{7,11}$, \\ Monica D. Nye ${ }^{6,8}$, Rebecca Fry ${ }^{9}$, David Skaar ${ }^{2}$, Rachel Maguire ${ }^{2}$, Amy Murtha $^{10}$, Joellen Schildkraut ${ }^{11}$, \\ Susan Murphy ${ }^{6}$ and Cathrine Hoyo ${ }^{2^{*}}$
}

\begin{abstract}
Background: Cadmium (Cd) is a ubiquitous and environmentally persistent toxic metal that has been implicated in neurotoxicity, carcinogenesis and obesity and essential metals including zinc (Zn) and iron (Fe) may alter these outcomes. However mechanisms underlying these relationships remain limited.

Methods: We examined whether maternal $C d$ levels during early pregnancy were associated with offspring DNA methylation at regulatory sequences of genomically imprinted genes and weight at birth, and whether Fe and $\mathrm{Zn}$ altered these associations. $\mathrm{Cd}$, Fe and $\mathrm{Zn}$ were measured in maternal blood of 319 women $\leq 12$ weeks gestation. Offspring umbilical cord blood leukocyte DNA methylation at regulatory differentially methylated regions (DMRs) of 8 imprinted genes was measured using bisulfite pyrosequencing. Regression models were used to examine the relationships among $\mathrm{Cd}, \mathrm{Fe}, \mathrm{Zn}$, and DMR methylation and birth weight.
\end{abstract}

Results: Elevated maternal blood Cd levels were associated with lower birth weight $(p=0.03)$. Higher maternal blood Cd levels were also associated with lower offspring methylation at the PEG3 DMR in females $(\beta=0.55$, se $=0.17, p=0.05)$, and at the MEG3 DMR in males $(\beta=0.72$, se $=0.3, p=0.08)$, however the latter association was not statistically significant. Associations between $\mathrm{Cd}$ and PEG3 and PLAGL1 DNA methylation were stronger in infants born to women with low concentrations of Fe $(p<0.05)$.

Conclusions: Our data suggest the association between pre-natal $\mathrm{Cd}$ and offspring DNA methylation at regulatory sequences of imprinted genes may be sex- and gene-specific. Essential metals such as Zn may mitigate DNA methylation response to $\mathrm{Cd}$ exposure. Larger studies are required.

Keywords: Cadmium, Zinc, Genomic imprinting, Epigenetics, Pediatrics, Obesity

\section{Background}

Cadmium $(\mathrm{Cd})$ is a naturally occurring toxic group IIb transition metal that is ubiquitous in the earth's crust. Increased anthropogenic utilization of $\mathrm{Cd}$ in the last several decades has led to increased human exposure at high doses; exposure vectors are wide ranging, including waste and emissions from mining, smelting, industrial activities, sewage sludge, tobacco smoking and fruit and vegetables contaminated by the use of phosphate fertilizers in agriculture [1]. Cd is a nephrotoxin, neurotoxicant, osteotoxicant, and carcinogen [2]. Cellular effects

\footnotetext{
* Correspondence: choyo@ncsu.edu

${ }^{2}$ Department of Biological Sciences, Center for Human Health and the Environment, North Carolina State University, Raleigh, NC 27695, USA Full list of author information is available at the end of the article
}

include apoptosis, DNA fragmentation and chromatin structural changes. Cd exposure has also been implicated in the etiology of fetal growth restriction [1, 3-5].

Zinc $(\mathrm{Zn})$, and iron $(\mathrm{Fe})$ are essential metals found in wheat, seeds, beans, seafood, and red meats as well as dietary supplements, and over-the-counter drugs [6]. Because $\mathrm{Zn}$ and $\mathrm{Fe}$ are co-factor for numerous enzymes involved in nucleic acid synthesis and repair, they play a significant role in growth, development, and cellular functions [7, 8]. Animal and cross-sectional human data suggest that at moderate levels, $\mathrm{Zn}$ and Fe may mitigate $\mathrm{Cd}$ effects via trans-metallation processes; however empirical data remain limited in human.

In vitro and in vivo studies demonstrated that exposure to Cd modifies DNA methylation patterns [9-12], 
although specific targets remain largely unknown. In humans, epigenetic targets for $\mathrm{Cd}$ exposure identified from unbiased approaches lack specificity, and the malleability of these epigenetic marks remains unknown. Moreover, although the timing of exposure during the life course is critical in determining severity of effects following exposure, human data is primarily from crosssectional studies and reports in adults.

Parental allele-specific differentially methylated regions (DMRs) of imprinted genes are established in the gametes and in the early embryo, and are generally stable in tissues from all germ layers. Perturbations in the establishment or maintenance of these DMRs during early embryogenesis can result in systemic variability that may be detected in nearly any tissue [13, 14]. Aberrant methylation at some imprint regulatory regions has been associated with lower birth weight [15].

In the present analysis, we examine the association between levels of $\mathrm{Zn}, \mathrm{Fe}$ and $\mathrm{Cd}$ in pregnant women and DNA methylation at imprinted regulatory DMRs in umbilical cord blood shown to be important in fetal growth and development or associated with other toxic metals including the H19 DMR regulating the IGF2/H19 domain, the MEG3 DMR regulating the MEG3 domain, the SGCE/PEG10 DMR positioned between Epsilon Sarcoglycan and Paternally Expressed Gene 10, the NNAT, MEST and PEG. We hypothesized Cd exposure in utero alters offspring DNA methylation levels in the DMRs regulating genomically imprinted NNAT, MEST, PEG3, PLAGL1, PEG10, IGF2, H19, and MEG3 DMRs and that maternal $\mathrm{Zn}$ and Fe levels alter these associations.

\section{Methods}

\section{Study participants}

Study participants were pregnant women who were enrolled as part of the Newborn Epigenetic STudy (NEST), a prospective cohort study of women and their offspring with the overarching goal of investigating the effects of in utero exposures on epigenetic profiles and phenotypes in children. Between 2009 and 2011, pregnant women were recruited from five prenatal clinics and obstetric care facilities at Duke University and Durham Regional Hospitals. Details of participant accrual have been previously described $[16,17]$. Eligibility criteria were age 18 years or older, pregnant and intending to use one of two participating obstetric facilities in Durham County for delivery. Excluded were women who planned to relinquish custody of the index child, move states in the subsequent 3 years, or had an established HIV infection. In the 18-month period between April, 2009 and 2011, 2,548 women were approached and 1,700 consented (66.7\% response rate). The present analyses are limited to the first 319 infant-mother pairs for whom maternal
Zn, Fe and Cd blood levels and infant DNA methylation were measured. Maternal race, smoking status, BMI before pregnancy, parity, delivery route, and education were comparable in the 319 infant-mother pairs included in this study and the remainder of the cohort $(p>0.05)$. The study protocol was approved by the Institutional Review Boards of Duke and North Carolina State Universities.

\section{Data and specimen collection}

Participants completed a self-administered questionnaire at the time of enrollment that included social and demographic characteristics, reproductive history, lifestyle factors, and anthropometric measurements. At study enrollment, maternal peripheral blood samples were collected; the mean gestational age at maternal blood draw was 12 weeks. Infant cord blood specimens were collected at birth. The leukocyte-containing buffy coat was isolated following centrifugation at $3500 \times \mathrm{g}$ for $20 \mathrm{~min}$ at $4{ }^{\circ} \mathrm{C}$. Aliquots were prepared and stored at $-80^{\circ} \mathrm{C}$.

\section{DNA methylation analysis}

Genomic DNA from buffy coat from umbilical cord blood specimens was extracted using PureGene reagents (Qiagen; Valencia, CA) and treated with sodium bisulfite using the Zymo EZ DNA Methylation Kit (Zymo Research, Irvine, CA). Bisulfite treatment modifies the DNA by converting unmethylated cytosines to uracils but leaves methylated cytosines unchanged. Pyrosequencing was performed using a Qiagen Pyromark Q96 MD Pyrosequencer. Primers and PCR conditions have been previously described $[18,19]$. The percent methylation for each CG dinucleotide was calculated using PyroQ CpG Software (Qiagen). The percent methylation was analyzed at multiple $\mathrm{CpG}$ sites for nine imprinted gene DMRs, including the maternally methylated NNAT, MEST, PEG3, PLAGL1, PEG10 DMRs and the paternally methylated IGF2, H19, and MEG3 DMRs.

\section{Measurement of $\mathrm{Cd}$, Fe and $\mathrm{Zn}$}

Maternal $\mathrm{Zn}, \mathrm{Fe}$ and $\mathrm{Cd}$ blood levels were measured in whole blood as nanograms per gram (ng/g; $1000 \mathrm{ng} / \mathrm{g}=$ $1025 \mathrm{ng} / \mu \mathrm{l}$ ) using well-established solution-based ICPMS methods [20-23]. Frozen maternal blood samples were equilibrated at room temperature, homogenized with a GlobalSpec laboratory slow shaker (GlobalSpec, East Greenbrush, NY) and $\sim 0.2 \mathrm{~mL}$ aliquots were pipetted into a trace-metal-clean test tube and verified gravimetrically to $\pm 0.001 \mathrm{mg}$ using a calibrated mass balance. Samples were then spiked with internal standards consisting of known quantities (10 and $1 \mathrm{ng} / \mathrm{g}$, respectively) of indium (In) and bismuth (Bi) (obtained from SCP Science), used to correct for instrumental drift. The 
solutions were then diluted using water purified to 18.2 $\mathrm{M} \Omega / \mathrm{cm}$ resistance (by a Milli-Q water purification system, Millipore, Bedford, Mass., USA) and acidified using ultra-pure $12.4 \mathrm{~mol} / \mathrm{L}$ hydrochloric acid to result in a final concentration of $2 \%$ hydrochloric acid (by volume). All standards, including aliquots of the certified NIST 955c, and procedural blanks were prepared by the same process.

$\mathrm{Zn}, \mathrm{Fe}$ and $\mathrm{Cd}$ concentrations were measured using a Perkin Elmer DRC II (Dynamic Reaction Cell) axial field ICP-MS at the University of MassachusettsBoston [20-23]. To clean sample lines and reduce memory effects, sample lines were sequentially washed with $18.2 \mathrm{M} \Omega \mathrm{cm}$ resistance (by a Milli-Q water purification system, Millipore, Bedford, Mass., USA) water for $90 \mathrm{~s}$ and a $2 \%$ nitric acid solution for $120 \mathrm{~s}$ between analyses. Procedural blanks were analyzed within each block of 10 samples, to monitor and correct for instrumental and procedural backgrounds. Calibration standards used to determine $\mathrm{Zn}$ and $\mathrm{Cd}$ in blood included aliquots of $18.2 \mathrm{M} \Omega \mathrm{cm}$ resistance $\mathrm{H}_{2} \mathrm{O}$, NIST 955c SRM, and NIST 955c SRM spiked with known quantities of each metal in a linear range from 0.025 to $10 \mathrm{ng} / \mathrm{g}$. Standards were prepared from $1000 \mathrm{mg} / \mathrm{L}$ single element standards obtained from SCP Science, USA. Method detection limits were calculated according to the two-step approach using the $t_{99} S_{\text {LLMV }}$ method (USEPA, 1993) at $99 \% \mathrm{CI}(\mathrm{t}=3.71)$. The MDLs for $\mathrm{Zn}$ and $\mathrm{Cd}$ yielded values of 278 and $83 \mathrm{pg} / \mathrm{g}$ parts per trillion, respectively. Limits of detection (LOD) and limits of quantification (LOQ) according to Long and Winefordner (1983) were less than $\sim 43 \mathrm{pg} / \mathrm{g}$ and $129 \mathrm{pg} / \mathrm{g}$ for $\mathrm{Zn}$, respectively and less than $\sim 17 \mathrm{pg} / \mathrm{g}$ and $51 \mathrm{pg} / \mathrm{g}$ for Cd, respectively.

\section{Measurement of folate}

Maternal whole blood samples were sent to Craft Technologies (Wilson, NC, USA) for measurement of erythrocyte folate using a commercial kit, ID-Vit Folic acid (Immundiagnostic-ALPCO; Salem, NH, Ref KIF005) which uses the folate dependent strain Lactobacillus rhamnosus (taxon id 47715) in a 96 well format.

\section{Statistical analyses}

Covariates considered for confounded were race/ethnicity (White, African American, Hispanic, and other), and parity (nulliparous and multiparous), physical activity ( $\geq 3$ days per week, yes/no), and maternal smoking (yes, no, and quit during pregnancy). Maternal $\mathrm{Zn}, \mathrm{Fe}$ and $\mathrm{Cd}$ blood levels were natural log transformed to achieve a normal distribution. Since at moderate levels, $\mathrm{Zn}$ and Fe have been shown to interact with $\mathrm{Cd}$ and to mitigate cellular, epigenetic and phenotypic effects in vivo and in vitro $[9,11,24,25]$, we explored these potential effects by categorizing $\mathrm{Zn}$ and Fe into high (top tertile) and low (bottom two tertiles) levels. We then modeled blood Cd on DMR methylation restricted to those with high and low levels of $\mathrm{Fe}$ or $\mathrm{Zn}$. Factors evaluated for confounding were maternal age at delivery (less than 30 years, 30-39 years, and older than 40 years), the mother's educational achievement (high school graduate/less and college/beyond), household income (less than $\$ 24,999$, $\$ 25,000-\$ 49,999, \quad \$ 50,000-\$ 100,000$, and more than $\$ 100,000$ per year), and BMI $\left(\mathrm{kg} / \mathrm{m}^{2}\right.$, normal $<25$, overweight $25-30$, obese $30-35$, and extremely obese $>35$ ) calculated from self-reported maternal weight before pregnancy at last menstrual period and measured height at the study visit. Pre-pregnancy weight was verified with the hospital medical charts. The accuracy of retrospectively capturing weight was evaluated by abstracting weight from medical records of 237 cohort members who visited a Duke clinic within 6 months of their first prenatal visit for the pregnancy that made them eligible for the study, including a subset of 43 had visited within three months of their first prenatal clinic visit. The correlation between periconceptional self-reported and nurse-measured weight was 0.95 in the 237 and 0.98 in the 43 participants, $(p<$ $0.0001)$. Parturition data examined included gestational age (preterm $<258$ days and term $>259$ days), delivery route (vaginal and C-Section) and birth weight (in grams). Given that maternal erythrocyte folate levels can affect DNA methylation, we used measurements of folate using methods previously described [15] based on a published protocol [26]. Since childhood obesity may vary by ethnicity/race, pre-pregnancy obesity, and sex, we also explored the potential for effect modification of the associations between $\mathrm{Cd}$ and DNA methylations and obesity in early childhood in African Americans, Hispanics and Whites. Final models were adjusted for maternal race, maternal smoking status, erythrocyte folate levels, parity, prenatal physical activity, infant sex and maternal pre-pregnancy BMI. All statistical analyses were conducted in Stata Version 13.0 (Stata Corp, 2013) using the xtmixed function, and findings were replicated in SAS. These analyses were repeated using logistic regression models where DNA methylation was dichotomized at the $4^{\text {th }}$ quartile, and weight at birth and age one year were categorized at $<2500,2500-4000$ and $>4000 \mathrm{~g}$ and $<85^{\text {th }}, 85-<$ $95^{\text {th }}$, and $>95^{\text {th }}$ percentile, respectively, and findings were comparable.

\section{Results}

\section{$\mathrm{Cd}$ and socio-demographic characteristics}

Maternal Cd levels did not vary by maternal age, prepregnancy obesity, gestational age at delivery, or by sex and birth weight of offspring. However, Cd levels were somewhat higher among Hispanic and African American women compared to White women $(p=0.03)$ (Table 1$)$. 
Cd blood concentrations were also higher among smoking mothers compared to nonsmoking mothers $(p=0.01)$, and were higher in women who delivered vaginally, compared to $\mathrm{C}$-section deliveries $(p=0.02)$. These factors were accounted for in multivariable analysis.

\section{Maternal Cd exposure and newborn DMR methylation}

We evaluated the association between maternal Cd levels and DNA methylation at 9 differentially methylated regions of genomically imprinted genes in the offspring. We found a significant association between maternal $\mathrm{Cd}$ concentrations and altered methylation at the DMR regulating

Table 1 Distribution of maternal blood cadmium concentrations (ng/g) $(n=319)$

\begin{tabular}{|c|c|c|c|c|}
\hline Characteristic & Number & Mean & SD & $p$-value \\
\hline Child Gender & & & & 0.73 \\
\hline Male & 164 & 4.43 & $(6.66)$ & \\
\hline Female & 155 & 4.65 & $(5.53)$ & \\
\hline Gestation Time & & & & 0.12 \\
\hline Preterm (<37 weeks) & 39 & 3.07 & $(4.70)$ & \\
\hline Normal( $\geq 37$ weeks) & 280 & 4.74 & $(6.28)$ & \\
\hline Birth Weight & & & & 0.61 \\
\hline Low Birth Weight (<2500) & 31 & 4.67 & $(5.93)$ & \\
\hline Normal Birth Weight(2500-<4600) & 281 & 4.58 & $(6.22)$ & \\
\hline High Birth Weight (>4600) & 5 & 1.84 & $(1.40)$ & \\
\hline Maternal Age & & & & 0.35 \\
\hline Less than 30 & 187 & 4.93 & $(6.24)$ & \\
\hline $30-39$ & 125 & 3.96 & $(6.08)$ & \\
\hline $40+$ & 7 & 4.28 & $(2.94)$ & \\
\hline Maternal Race & & & & 0.03 \\
\hline African American & 111 & 4.71 & $(4.65)$ & \\
\hline White & 95 & 3.13 & $(5.07)$ & \\
\hline Hispanic & 101 & 5.44 & $(7.63)$ & \\
\hline Other & 12 & 6.48 & $(9.51)$ & \\
\hline Maternal BMI & & & & 0.48 \\
\hline Less than 18.5 & 9 & 5.39 & $(7.46)$ & \\
\hline 18.5 to less than 25 & 111 & 4.20 & $(5.83)$ & \\
\hline 25 to less than 30 & 78 & 4.88 & $(5.90)$ & \\
\hline 30 to less than 35 & 39 & 2.95 & $(3.55)$ & \\
\hline $35+$ & 29 & 3.87 & $(4.25)$ & \\
\hline Maternal Smoking Status & & & & 0.01 \\
\hline Smoking Prior to Pregnancy & 39 & 2.56 & (3.13) & \\
\hline Smoking During Pregnancy & 46 & 6.44 & $(4.79)$ & \\
\hline Never Smoke & 225 & 4.42 & $(6.59)$ & \\
\hline Delivery Route & & & & 0.02 \\
\hline Vaginal & 198 & 5.16 & $(6.72)$ & \\
\hline Cesarean section & 120 & 3.50 & $(4.88)$ & \\
\hline
\end{tabular}

PEG3 ( $\beta=0.36$, se $=0.17 p=0.03)$. We also found associations of borderline significance between maternal $\mathrm{Cd}$ concentrations and altered methylation at the DMRs regulating MEG3 ( $\beta=0.44$, se $=0.30, p=0.14)$, and NNAT ( $\beta=0.54$, se $=0.32, p=0.09)$ (Table 2).

Associations may be specific to females at the PEG3 $(\beta=0.55, p=0.05)$ but not in males $(\beta=0.09, p=0.61)$; whereas associations with the MEG3 ( $\beta=0.72$, se $=0.41$, $p=0.08$ ), and MEST (beta $=0.47$, se $=0.29, p=0.10$ ) DMRs may be specific to males and less evident in females. No evidence for sex-specific association at other DMRs was found.

Despite higher levels of $\mathrm{Cd}$ in Hispanics, restricting these analyses by self-reported ethnicity/race and further adjusting for sex of offspring revealed other consistent associations between $\mathrm{Cd}$ exposure and regulatory DMR methylation (data not shown).

\section{Maternal Fe and $\mathrm{Zn}$ abundance in associations between $\mathrm{Cd}$ and DNA methylation at regulatory sequences of genomically imprinted genes}

We also explored the extent to which maternal $\mathrm{Zn}$ and Fe altered the pattern of the associations observed between maternal $\mathrm{Cd}$ and offspring DNA methylation at the MEG3, PLAGL1 and PEG3, by repeating the refined models, restricted to women and children with high concentrations of $\mathrm{Zn}$ or $\mathrm{Fe}$ (top tertile), and again among those with low levels (bottom two tertiles) (Fig. 1). We observed that higher $\mathrm{Cd}$ levels were associated with lower PLAGL1 DMR methylation levels in women with lower $\mathrm{Zn}$ and Fe levels (Fig. 1a); the crossproduct term for the interaction between $\mathrm{Zn}$ and $\mathrm{Cd}$ was $p=0.04$, and that for $\mathrm{Cd}$ and Fe was $(p=0.37)$. We also found that higher PEG3 DMR methylation levels were associated with higher $\mathrm{Cd}$ concentrations, but this association appeared limited to women with $\mathrm{Zn}$ levels in the top tertile $(p<0.05)$ (Fig. 1b). The cross-product term for the interaction between $\mathrm{Cd}$ and $\mathrm{Zn}$ was $p=0.01$. This positive association between elevated $\mathrm{Cd}$ levels and higher

Table 2 Regression coefficients, standard errors and $p$-values for the association between maternal blood cadmium exposure and offspring DNA methylation at DMRs imprinted genes

\begin{tabular}{llll}
\hline DMRs & All & Males & Females \\
& $\beta$, SE, P-value & $\beta$, SE, $P$-value & $\beta$, SE, $p$-value \\
\hline IGF2/H19 & $-0.02,0.18,0.91$ & $0.06,0.25,0.80$ & $-0.20,0.25,0.42$ \\
MEG3 & $0.44,0.30,0.14$ & $0.72,0.41,0.08$ & $0.37,0.42,0.38$ \\
MEST & $0.05,0.22,0.83$ & $0.47,0.29,0.10$ & $-0.34,0.34,0.31$ \\
NNAT & $0.54,0.32,0.09$ & $0.61,0.45,0.17$ & $0.41,0.48,0.39$ \\
PEG3 & $0.36,0.17,0.03$ & $0.09,0.17,0.61$ & $0.55,0.28,0.05$ \\
SGCE/PEG10 & $0.01,0.19,0.98$ & $-0.23,0.26,0.36$ & $0.38,0.28,0.18$ \\
PLAGL1 & $-0.20,0.34,0.56$ & $-0.42,0.50,0.40$ & $-0.17,0.48,0.72$ \\
\hline
\end{tabular}




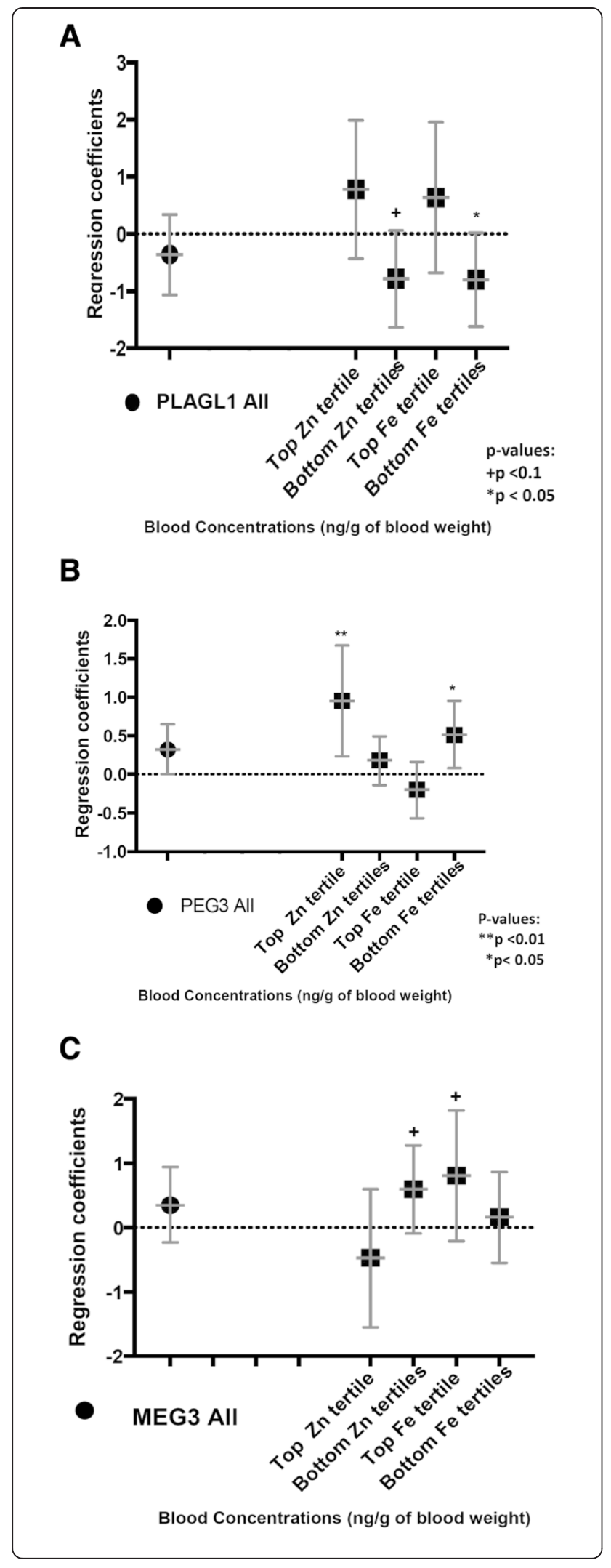

Fig. 1 Regression coefficients for the associations between maternal $\mathrm{Cd}$ and DNA methylation at newborns imprinted genes. a. Infants born to women with high blood $\mathrm{Cd}$ concentrations but with lower Zn and Fe levels, had lower DNA methylation at the PLAGL1 DMR. b. Maternal higher $\mathrm{Zn}$ and $\mathrm{Cd}$ concentrations were associated with higher methylation at the PEG3 DMR in newborns. c. No associations were observed for MEG3

PEG3 methylation was similar in women with high and low Fe levels (Fig. 1b); the cross-product term for the interaction between $\mathrm{Fe}$ and $\mathrm{Cd}$ was $p=0.45$. We also found no evidence that the association between $\mathrm{Cd}$ levels and MEG3 DMR methylation varied by Fe and $\mathrm{Zn}$ nutrient abundance (Fig. 1c).

\section{Cd levels and birth weight}

As Cd placental sequestration has been associated with fetal growth restriction; consequently, we also evaluated whether maternal $\mathrm{Cd}$ levels were associated with birth weight (Table 3). We found that higher maternal $\mathrm{Cd}$ concentrations in blood were associated with lower birth weight $(\beta=-51.89$, $\mathrm{se}=24.20, p=0.03)$.

\section{Discussion}

While the known effects of $\mathrm{Cd}$ include replacement of essential protein cofactors, protein disruption/misfolding, generation of oxidative stress, and endocrine disruption, epigenetic mechanisms are emerging as a dynamic

Table 3 Associations between maternal cadmium levels and birth weight

\begin{tabular}{llll}
\hline & \multicolumn{3}{l}{$\begin{array}{l}\text { Adjusted associations of Log Cd and } \\
\text { birth weight }(n=276)\end{array}$} \\
\cline { 2 - 4 } & $\beta$ & se & $\mathrm{p}$ \\
\hline Maternal & -51.89 & 24.20 & 0.03 \\
Log Cd & & \\
a Race/Ethnicity & -237.73 & 70.38 & 0.00 \\
NH Black & -164.34 & 72.27 & 0.02 \\
Hispanic & -222.72 & 134.09 & 0.10 \\
NH Other & & & \\
Smoking & -173.52 & 106.27 & 0.10 \\
Smoking during pregnancy & -12.21 & 85.77 & 0.89 \\
Quit during pregnancy & 13.68 & 3.99 & 0.00 \\
Pre-Pregnancy BMl & 5.23 & 64.31 & 0.94 \\
Prenatal physical Activity & -94.61 & 60.38 & 0.12 \\
Periconceptional antibiotic use & & & \\
Offspring & & 52.19 & 0.04 \\
Female & -107.72 & 2.19 & 0.00 \\
Gestational Age at Delivery & 26.48 & 633.10 & 0.00 \\
Constant & -3996.97 & & \\
\hline Chact & & & \\
\hline
\end{tabular}

Characteristics mutually adjusted

${ }^{\mathrm{a}}$ Referents are non-Hispanic whites 
mechanistic framework for how the environment interacts with the genome to influence low birth weight and cardio metabolic risk in later life. However, regions of the human epigenome targeted by these ubiquitous toxic metals are still unknown. Moreover, there is limited empirical longitudinal human data on the role of essential metals such as $\mathrm{Zn}$ and Fe, previously shown to be antagonists to Cd absorption in animal models [24, 25]. We conducted an analysis to determine whether maternal $\mathrm{Cd}$ concentrations, are associated with birth weight, DNA methylation alterations at multiple DMRs regulating genomically imprinted genes after accounting for maternal race/ethnicity, antibiotic use, physical activity, parity, cigarette smoking and sex. We also evaluated the extent to which the abundance of the essential minerals, $\mathrm{Zn}$ and Fe modify this association.

Our key finding was that elevated $\mathrm{Cd}$ levels were significantly associated with higher DNA methylation at the DMR regulating PEG3; these associations varied by $\mathrm{Zn}$ or Fe circulating levels. We also found that higher maternal $\mathrm{Cd}$ levels were associated with lower birth weight. Our data support that early $\mathrm{Cd}$ exposure is gene-specific as DNA methylation of several other DMRs evaluated in newborns were not associated with prenatal levels of $\mathrm{Cd}$. DNA methylation at these regulatory DMRs are established in gametogenesis and embryogenesis and may be vulnerable to availability/ abundance of circulating essential metals, including $\mathrm{Fe}$ and Zn. DNA methylation marks here examined have previously been associated with fetal development. If these findings are replicated in a larger study and from a wider scope of regulatory regions, our findings suggest that nutritional manipulation during vulnerable periods in life could alter disease course, in Cd-exposed populations. Moreover, if these epigenetic marks are confirmed to be stable in humans, these regions could be developed as markers of periconceptional $\mathrm{Cd}$ exposure, for potential use in risk assessment.

Our data suggest that $\mathrm{Cd}$ concentrations during early pregnancy are associated with lower levels of newborn's DNA methylation at the DMR regulating PEG3, and less consistently at IGF2/H19 and MEG3 and none with PLAGL1 imprinted domains. PEG3 is a paternally expressed imprinted gene, maps to chromosome 19q13.43 and encodes a zinc finger protein with a tumor suppressor function that plays a role in facilitating p53/c-myc-mediated apoptosis. PEG3 also plays a critical role in brain development where it is mainly expressed in the mesencephalon and the pituitary gland [27]. Shifts in DNA methylation at the PEG3 DMR have been shown to alter social and maternal nurturing behaviors in mice $[27,28]$ and to be associated with human cancer [19], presumably caused by a decrease in PEG3 transcription $[29,30]$. In support, a long term follow-up study, lower
PEG3 DMR methylation was recently associated with exposure to lead, a +2 toxic metal that tends to cooccur with $\mathrm{Cd}$ ( $\mathrm{Li}$ et al., in press). Lower DNA methylation levels at the same PEG3 DMR in males and IGF2/ H19 DMR in females have been associated with exposure to another environmentally abundant neurotoxin, lead, during the neonatal period (Li et al., in press).

While we know of no other study that has examined $\mathrm{Cd}$ exposure in relation to epigenetic dysregulation specifically targeting genomically imprinted genes, our findings that $\mathrm{Cd}$ exposure in utero is associated with DNA methylation differences is consistent with in vitro and ex-vivo systems studies showing that $\mathrm{Cd}$ is an effective inhibitor of DNA methyltransferase. Specifically, Cd initially induces DNA hypomethylation, although prolonged $\mathrm{Cd}$ exposure results in DNA hypermethylation and enhanced DNA methyltransferase activity [9]. In humans, gene-specific studies based on known gene function have shown DNA methylation alterations in response to Cd exposure [31, 32]; however, few have been conducted at birth to reflect the periconceptional environment [12]. Using the unbiased Illumina HumanMethylation450 BeadChip, maternal cigarette smoking, a common source of fetal $\mathrm{Cd}$ exposure, has been associated with altered DNA methylation at multiple CpG sites including 11 imprinted genes such as AHRR, GFI1, IGF2 and CYP1A1 in cord blood leukocyte DNA [33, 34]. In studies with small sample sizes [12, 35], in utero Cd exposure specifically was associated with $\mathrm{CpG}$ methylation differences in umbilical cord blood leukocyte DNA at multiple CpG sites mapping to genes involved in xenobiotic metabolism and inflammation [12], some of which may be sex-specific $[36,37]$. Female-specific effects of $\mathrm{Cd}$ exposure have previously been reported in relation to birth weight, hypothesized to be due to lower iron in females that is associated with increased Cd intestinal absorption [38]. Therefore, while findings from these gene-specific and genome-scale studies do not include regions regulating PLAGL1, MEG3 and PEG3 examined here, together they support that in utero $\mathrm{Cd}$ exposure alters the epigenome.

Our findings that the association among maternal $\mathrm{Cd}$ and $\mathrm{CpG}$ methylation vary by $\mathrm{Zn}$ and Fe concentrations are consistent with the toxicity of these essential metals when present in excess, and reduced intestinal absorption reported in animal models. Both $\mathrm{Zn}$ and Fe have been shown to mitigate cellular, epigenetic and phenotypic effects in vivo and in vitro $[9,11,23,24,39]$. Mechanisms by which Fe or Zn may decrease harmful effects of $\mathrm{Cd}$ exposure remain unknown, although are an active topic of investigation. Studies suggest that marginal intakes of $\mathrm{Zn}, \mathrm{Fe}$, and $\mathrm{Ca}$ cause the accumulation of $\mathrm{Cd}$ in the duodenum, which results in a greater rate of $\mathrm{Cd}$ absorption and a greater accumulation in the 
internal organs $[24,25]$, which may influence fetal development and epigenetic dysregulation. However, these associations may also depend on other essential elements as well as age and sex. Cd may compete with essential metals for binding to transporter molecules. Indeed, $\mathrm{Fe}$ deficiency has been shown to upregulate Fe transporters and subsequently, increased $\mathrm{Cd}$ in duodenal mucosa $[40,41]$. Deficiencies or excesses of these essential metals can contribute to epigenetic alterations and/or other mechanisms to influence phenotypes such as birth weight and childhood obesity [42], associations that may vary by race/ethnicity as our present results suggest. $\mathrm{Zn}$ and $\mathrm{Fe}$ are essential co-factor for many enzymes that epigenetically modify DNA and histones, and maternal $\mathrm{Zn}$ excess or deficiencies may program offspring growth trajectories by altering epigenetic modifications of DNA and histones [39, 43, 44] at labile loci. Together, our findings corroborate animal and in vitro data $[9,24,25]$.

A strength of our study is its longitudinal design in early life, as few studies examine $\mathrm{Cd}$ exposure before birth. Because $\mathrm{Cd}$ and $\mathrm{Zn}$ measurements were made in erythrocytes at gestational age $<12$ weeks, and many heavy metals bind to erythrocytes (a 120 day lifespan), metal concentrations examined here likely represent those of the periconceptional environment. As nutrient concentrations vary by ethnicity (NHANES), another strength is the multiethnic composition of the cohort, enabling examination of the effects of $\mathrm{Cd}$ and $\mathrm{Zn}$ on the four major ethnic group in the US: Whites, Blacks, Hispanics and Asians. However, given race/ethnic heterogeneity, we cannot exclude the possibility that our inability to find statistically significant associations between altered methylation at other DMRs in response to $\mathrm{Cd}$ exposure could be due, in part, to our limited statistical power in race-specific analyses. While statistical power was adequate for overall analyses, we are underpowered for examining higher-order interaction by race. Also, we examined only eight DMRs of more than 65 genes currently known to be imprinted in humans, these 65 genes themselves represent only 1$5 \%$ of the human genome [45]. Analysis of the methylation status of a wider spectrum of the epigenome will be required to clarify the spectrum of genes and pathways that contribute to the association between maternal $\mathrm{Cd}$ and DNA methylation alterations in newborns. Despite these limitations, our data suggest that maternal exposure to $\mathrm{Cd}$ is associated with aberrant DNA methylation at multiple regions previously associated with preterm birth [46], fetal growth restriction and neurodevelopmental disorders, as previously reported in other geographic regions [36, 47]. With replication, PLAGL1 and PEG3 could be considered among epigenetic regions perturbed by $\mathrm{Cd}$ exposure early in utero.

\section{Conclusions}

Although epigenetic mechanisms have been proposed to link early $\mathrm{Cd}$ exposure to human health, human data are still limited, as epigenetic targets that may influence human health are still unknown. We present data consistent with the hypothesis that maternal $\mathrm{Cd}$ exposure in early pregnancy alters DNA methylation at multiple DMRs in offspring with sex and possibly race/ethnicspecific effects, and that $\mathrm{Zn}$ may mitigate these effects. We also contribute data suggesting that early $\mathrm{Cd}$ exposure is associated with lower birth weight. As our data were too limited for mediation analyses, larger studies are required to confirm these findings and to determine the role of other imprinted and non-imprinted genes in the associations between $\mathrm{Cd}, \mathrm{Fe}$ and $\mathrm{Zn}$ exposure in epigenetic alterations with known methylation profiles, and low birth weight, a consistent risk factor for childhood obesity and other chronic diseases. Such efforts would contribute data to nutritional policy related to these ubiquitous toxic metals.

\section{Abbreviations}

Cd: Cadmium; Fe: Iron; Zn: Zinc; DMR: Differentially methylated region.

\section{Competing interests}

The authors declare that they have no competing interests.

\section{Authors' contributions}

$\mathrm{ZH}$ and DS performed the experiments. SM, AM and $\mathrm{CH}$ supervised the data collection and experimental work. RM managed the data. SV, TD, AV, ACV and RF contributed in the analysis and interpretation of the data. SV, ACV and $\mathrm{CH}$ were involved in drafting the manuscript. TD, AV, KK, MN, AM, and $J \mathrm{~S}$, critically revised the manuscript for important intellectual content. $\mathrm{CH}$ conceived of the study, and participated in its design and coordination. All authors read and approved the final manuscript.

\section{Acknowledgments}

This work was supported by National Institutes of Health grants ES016772 and ES005948 and greatly benefited from funding by the National Children's Study Placental Consortium (NCS Formative Research Project LOI2-BIO-18) to THD (NIH: NO1-HD-5-3422) and an ORISE Fellowship to KK. This work does not represent the official view of the US EPA. We thank Carole Grenier, Erin Erginer, Allison Barratt, Cara Davis, and Alissa White for excellent technical support.

\section{Author details}

${ }^{1}$ Department of Surgery, Division of Urology, Cedars-Sinai Medical Center, Los Angeles, CA 90048, USA. ²Department of Biological Sciences, Center for Human Health and the Environment, North Carolina State University, Raleigh, NC 27695, USA. ${ }^{3}$ Department of Public Health, Brody School of Medicine, East Carolina University, Greenville, NC 27834, USA. ${ }^{4}$ Division of Water, Climate, and the Environment, School of Earth Sciences, The Ohio State University, Columbus, OH 43210, USA. ${ }^{5}$ Nicholas School of the Environment, Duke University, Research Drive, Durham, NC 27710, USA. ${ }^{6}$ Division of Gynecologic Oncology, Department of Obstetrics and Gynecology, Duke University School of Medicine, Research Drive, Durham, NC 27710, USA. ${ }^{7}$ Environmental Public Health Division, U.S. Environmental Protection Agency, Chapel Hill, NC 27599, USA. ${ }^{8}$ University of North Carolina at Chapel Hill, Lineberger Comprehensive Cancer Center, 450 West Drive, Chapel Hill, NC 27599, USA. ${ }^{9}$ Department of Environmental Sciences and Engineering, Gillings School of Global Public Health, UNC-Chapel Hill, Chapel Hill, NC 27599, USA. ${ }^{10}$ Division of Maternal Fetal Medicine, Department of Obstetrics and Gynecology, Duke University School of Medicine, Erwin Drive, Durham, NC 27710, USA. ${ }^{11}$ Department of Community and Family Medicine and Duke 
Cancer Institute, Duke University School of Medicine, Erwin Drive, Durham, NC 27710, USA.

\section{Received: 16 January 2015 Accepted: 7 July 2015 Published online: 15 July 2015}

\section{References}

1. Cadmium [http://toxtown.nlm.nih.gov/text_version/chemicals.php?id=63]

2. Registry: http://www.atsdr.cdc.gov/. 2011.

3. Hou L, Zhang X, Wang D, Baccarelli A. Environmental chemical exposures and human epigenetics. Int J Epidemiol. 2012;41(1):79-105.

4. Menai M, Heude B, Slama R, Forhan A, Sahuquillo J, Charles MA, et al. Association between maternal blood cadmium during pregnancy and birth weight and the risk of fetal growth restriction: the EDEN mother-child cohort study. Reprod Toxicol. 2012;34(4):622-7.

5. Scott ME, Shvetsov YB, Thompson PJ, Hernandez BY, Zhu X, Wilkens LR, et al. Cervical cytokines and clearance of incident human papillomavirus infection: Hawaii HPV cohort study. Int J Cancer. 2013;133(5):1187-96.

6. Zinc: Fact Sheet for Health Professionals [http://ods.od.nih.gov/factsheets/ Zinc-HealthProfessional/].

7. Matovic V, Buha A, Bulat Z, Dukic-Cosic D. Cadmium toxicity revisited: focus on oxidative stress induction and interactions with zinc and magnesium. Arh Hig Rada Toksikol. 2011;62(1):65-76.

8. Rogalska J, Brzoska MM, Roszczenko A, Moniuszko-Jakoniuk J. Enhanced zinc consumption prevents cadmium-induced alterations in lipid metabolism in male rats. Chem Biol Interact. 2009;177(2):142-52.

9. Takiguchi M, Achanzar WE, Qu W, Li G, Waalkes MP. Effects of cadmium on DNA-(Cytosine-5) methyltransferase activity and DNA methylation status during cadmium-induced cellular transformation. Exp Cell Res. 2003;286(2):355-65.

10. Reichard JF, Schnekenburger M, Puga A. Long term low-dose arsenic exposure induces loss of DNA methylation. Biochem Biophys Res Commun. 2007;352(1):188-92.

11. Jiang $G, X u L$, Song $S$, Zhu C, Wu Q, Zhang L, et al. Effects of long-term low-dose cadmium exposure on genomic DNA methylation in human embryo lung fibroblast cells. Toxicology. 2008;244(1):49-55.

12. Sanders AP, Smeester L, Rojas D, Debussycher T, Wu MC, Wright FA, et al. Cadmium exposure and the epigenome: Exposure-associated patterns of DNA methylation in leukocytes from mother-baby pairs. Epigenetics. 2014;9(2):212-21.

13. Woodfine K, Huddleston JE, Murrell A. Quantitative analysis of DNA methylation at all human imprinted regions reveals preservation of epigenetic stability in adult somatic tissue. Epigenetics Chromatin. 2011:4(1):1.

14. Hoyo C, Murphy SK, Jirtle RL. Imprint regulatory elements as epigenetic biosensors of exposure in epidemiological studies. J Epidemiol Community Health. 2009;63(9):683-4.

15. Hoyo C, Daltveit AK, Iversen E, Benjamin-Neelon SE, Fuemmeler B, Schildkraut J, et al. Erythrocyte folate concentrations, $\mathrm{CpG}$ methylation at genomically imprinted domains, and birth weight in a multiethnic newborn cohort. Epigenetics. 2014;9(8):1120-30.

16. Liu Y, Murphy SK, Murtha AP, Fuemmeler BF, Schildkraut J, Huang Z, et al. Depression in pregnancy, infant birth weight and DNA methylation of imprint regulatory elements. Epigenetics. 2012;7(7):735-46.

17. Vidal AC, Murphy SK, Murtha AP, Schildkraut JM, Soubry A, Huang Z, et al. Associations between antibiotic exposure during pregnancy, birth weight and aberrant methylation at imprinted genes among offspring. Int J Obes (Lond). 2013;37(7):907-13.

18. Murphy SK, Huang Z, Hoyo C. Differentially methylated regions of imprinted genes in prenatal, perinatal and postnatal human tissues. PLoS One. 2012;7(7), e40924.

19. Nye MD, Hoyo C, Huang Z, Vidal AC, Wang F, Overcash F, et al. Associations between methylation of paternally expressed gene 3 (PEG3), cervical intraepithelial neoplasia and invasive cervical cancer. PLoS One. 2013;8(2), e56325.

20. Darrah TH, Prutsman-Pfeiffer JJ, Poreda RJ, Ellen Campbell M, Hauschka PV, Hannigan RE. Incorporation of excess gadolinium into human bone from medical contrast agents. Metallomics. 2009;1(6):479-88.

21. DeLoid G, Cohen JM, Darrah T, Derk R, Rojanasakul L, Pyrgiotakis G, et al. Estimating the effective density of engineered nanomaterials for in vitro dosimetry. Nat Commun. 2014;5:3514.
22. McLaughlin MP, Darrah TH, Holland PL. Palladium(II) and platinum(II) bind strongly to an engineered blue copper protein. Inorg Chem. 2011;50(22):11294-6.

23. Sprauten M, Darrah TH, Peterson DR, Campbell ME, Hannigan RE, Cvancarova M, et al. Impact of long-term serum platinum concentrations on neuro- and ototoxicity in Cisplatin-treated survivors of testicular cancer. J Clin Oncol. 2012;30(3):300-7.

24. Reeves PG, Chaney RL. Marginal nutritional status of zinc, iron, and calcium increases cadmium retention in the duodenum and other organs of rats fed rice-based diets. Environ Res. 2004;96(3):311-22.

25. Brzoska MM, Moniuszko-Jakoniuk J. Interactions between cadmium and zinc in the organism. Food Chem Toxicol. 2001;39(10):967-80.

26. Piyathilake CJ, Robinson CB, Cornwell P. A practical approach to red blood cell folate analysis. Anal Chem Insights. 2007;2:107-10.

27. Li L, Keverne EB, Aparicio SA, Ishino F, Barton SC, Surani MA. Regulation of maternal behavior and offspring growth by paternally expressed Peg3. Science. 1999;284(5412):330-3.

28. Chiavegatto S, Sauce B, Ambar G, Cheverud JM, Peripato AC. Hypothalamic expression of Peg3 gene is associated with maternal care differences between SM/J and LG/J mouse strains. Brain Behav. 2012;2(4):365-76.

29. Deng Y, Wu X. Peg3/Pw1 promotes p53-mediated apoptosis by inducing Bax translocation from cytosol to mitochondria. Proc Natl Acad Sci U S A. 2000;97(22):12050-5

30. Johnson MD, Wu X, Aithmitti N, Morrison RS. Peg3/Pw1 is a mediator between p53 and Bax in DNA damage-induced neuronal death. J Biol Chem. 2002;277(25):23000-7.

31. Arita A, Shamy MY, Chervona Y, Clancy HA, Sun H, Hall MN, et al. The effect of exposure to carcinogenic metals on histone tail modifications and gene expression in human subjects. J Trace Elem Med Biol. 2012;26(2-3):174-8.

32. Hossain MB, Vahter M, Concha G, Broberg K. Low-level environmental cadmium exposure is associated with DNA hypomethylation in Argentinean women. Environ Health Perspect. 2012;120(6):879-84.

33. Joubert BR, Haberg SE, Nilsen RM, Wang X, Vollset SE, Murphy SK, et al. $450 \mathrm{~K}$ epigenome-wide scan identifies differential DNA methylation in newborns related to maternal smoking during pregnancy. Environ Health Perspect. 2012;120(10):1425-31.

34. Murphy SK, Adigun A, Huang Z, Overcash F, Wang F, Jirtle RL, et al. Gender-specific methylation differences in relation to prenatal exposure to cigarette smoke. Gene. 2012;494(1):36-43.

35. Smeester L, Yosim AE, Nye MD, Hoyo C, Murphy SK, Fry RC. Imprinted genes and the environment: links to the toxic metals arsenic, cadmium, lead and mercury. Genes (Basel). 2014;5(2):477-96.

36. Kippler M, Engstrom K, Mlakar SJ, Bottai M, Ahmed S, Hossain MB, et al. Sex-specific effects of early life cadmium exposure on DNA methylation and implications for birth weight. Epigenetics. 2013;8(5):494-503.

37. Kippler M, Tofail F, Hamadani JD, Gardner RM, Grantham-McGregor SM, Bottai $\mathrm{M}$, et al. Early-life cadmium exposure and child development in 5-year-old girls and boys: a cohort study in rural Bangladesh. Environ Health Perspect. 2012;120(10):1462-8.

38. Akesson A, Berglund M, Schutz A, Bjellerup P, Bremme K, Vahter M. Cadmium exposure in pregnancy and lactation in relation to iron status. Am J Public Health. 2002;92(2):284-7.

39. Maret W, Sandstead HH. Possible roles of zinc nutriture in the fetal origins of disease. Exp Gerontol. 2008:43(5):378-81.

40. Min KS, Iwata N, Tetsutikawahara N, Onosaka S, Tanaka K. Effect of hemolytic and iron-deficiency anemia on intestinal absorption and tissue accumulation of cadmium. Toxicol Lett. 2008;179(1):48-52.

41. Flanagan PR, McLellan JS, Haist J, Cherian G, Chamberlain MJ, Valberg LS. Increased dietary cadmium absorption in mice and human subjects with iron deficiency. Gastroenterology. 1978;74(5 Pt 1):841-6.

42. Yang QY, Liang JF, Rogers CJ, Zhao JX, Zhu MJ, Du M. Maternal obesity induces epigenetic modifications to facilitate Zfp 423 expression and enhance adipogenic differentiation in fetal mice. Diabetes. 2013;62(11):3727-35.

43. Fatemi M, Hermann A, Pradhan S, Jeltsch A. The activity of the murine DNA methyltransferase Dnmt1 is controlled by interaction of the catalytic domain with the $\mathrm{N}$-terminal part of the enzyme leading to an allosteric activation of the enzyme after binding to methylated DNA. J Mol Biol. 2001;309(5):1189-99.

44. Somoza JR, Skene RJ, Katz BA, Mol C, Ho JD, Jennings AJ, et al. Structural snapshots of human HDAC8 provide insights into the class I histone deacetylases. Structure. 2004;12(7):1325-34. 
45. Luedi PP, Dietrich FS, Weidman JR, Bosko JM, Jirtle RL, Hartemink AJ. Computational and experimental identification of novel human imprinted genes. Genome Res. 2007;17(12):1723-30.

46. Liu Y, Hoyo C, Murphy S, Huang Z, Overcash F, Thompson J, et al. DNA methylation at imprint regulatory regions in preterm birth and infection. Am J Obstet Gynecol. 2013;208(5):e391-7. 395.

47. Kippler M1, Tofail F, Gardner R, Rahman A, Hamadani JD, Bottai M, et al. Maternal cadmium exposure during pregnancy and size at birth: a prospective cohort study. Environ Health Perspect. 2012;120(2):284-9.

\section{Submit your next manuscript to BioMed Central} and take full advantage of:

- Convenient online submission

- Thorough peer review

- No space constraints or color figure charges

- Immediate publication on acceptance

- Inclusion in PubMed, CAS, Scopus and Google Scholar

- Research which is freely available for redistribution 